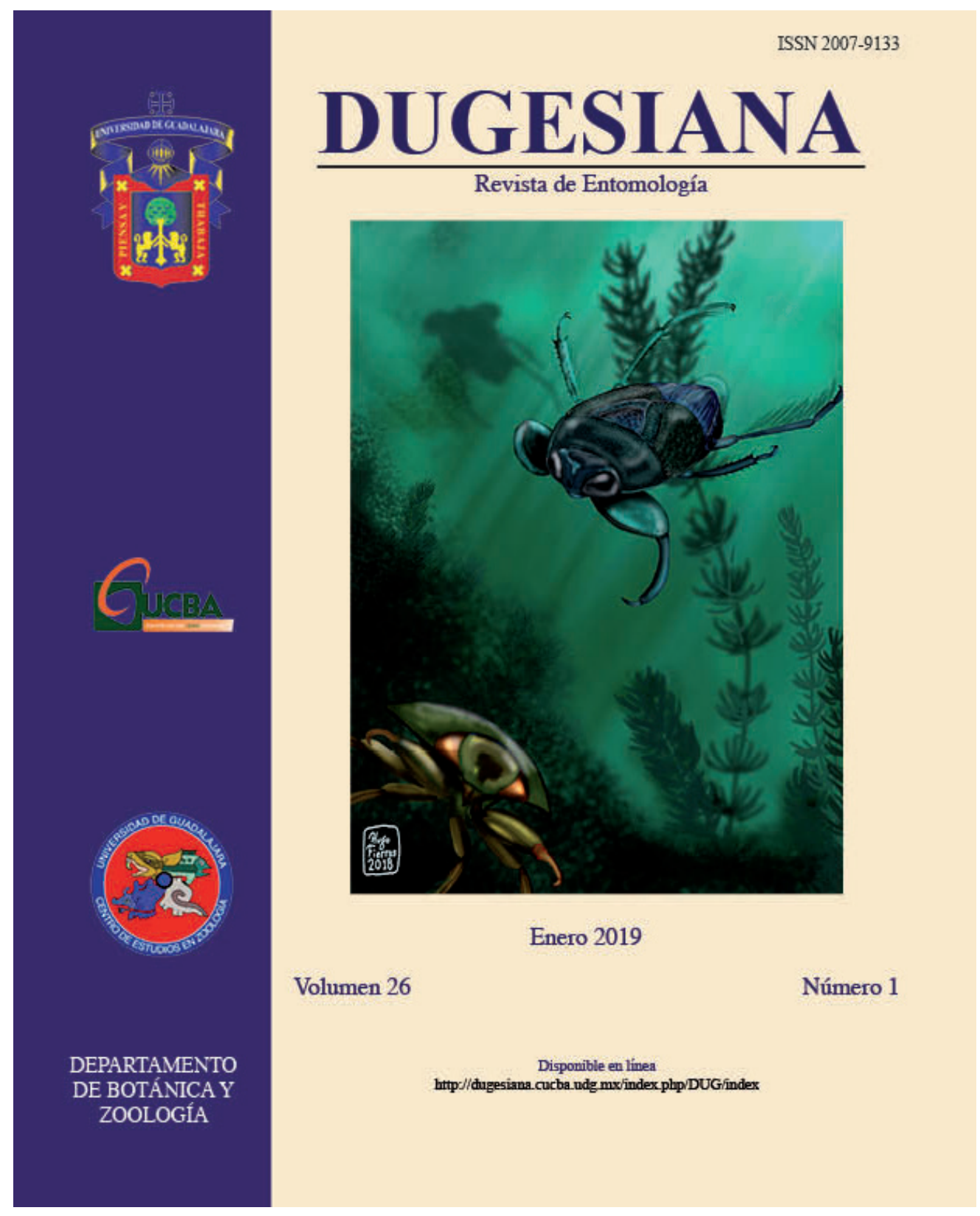

DUGESIANA, Año 26, No.1, 2019 (primer semestre de 2019) es una publicación Semestral editada por la Universidad de Guadalajara, a través del Centro de Estudios en Zoología, por la División de Ciencias Biológicas y Ambientales, CUCBA. Km. 15.5 carr. a Nogales, Predio Las Agujas s/n, Nextipac, C.P. 45100. Zapopan, Jalisco, México. Tel. 37771150, http://dugesiana.cucba.udg.mx/index.php/DUG/index, glenusmx@gmail.com, Editor responsable: José Luis Navarrete Heredia. Reserva de Derechos al Uso Exclusivo 04-2009-062310115100-203, ISSN: 2007-9133, otorgados por el Instituto Nacional del Derecho de Autor. Responsable de la última actualización de este número: José Luis Navarrete Heredia, Editor y Ana Laura González-Hernández, Asistente Editorial. Fecha de la última modificación 1 de enero de 2019, con un tiraje de un ejemplar.

Las opiniones expresadas por los autores no necesariamente reflejan la postura del editor de la publicación.

Queda estrictamente prohibida la reproducción total o parcial de los contenidos e imágenes de la publicación sin previa autorización de la Universidad de Guadalajara. 


\section{Primer registro de Ariamnes mexicanus (Exline y Levi, 1962) (Araneae: Theridiidae) para Hidalgo, México}

\section{First record of Ariamnes mexicanus (Exline y Levi, 1962) (Araneae: Theridiidae) in Hidalgo, Mexico}

\section{Itzcóatl Martínez-Sánchez ${ }^{1}$ y David Chamé-Vázquez ${ }^{2 *}$}

${ }^{1}$ Unidad Académica Metztitlán, Universidad Politécnica de Francisco I. Madero. C.P. 43351. Metztitlán, Hidalgo, México. itzcomtz@gmail.com; ${ }^{2}$ Colección de Arácnidos del Sureste de México, El Colegio de la Frontera Sur. C.P. 30700, Tapachula, Chiapas, México. *Autor de correspondencia: chamevazquez@gmail.com.

Las arañas del género Ariamnes Thorell, 1869 son fácilmente distinguibles de otros géneros de la subfamilia Argyrodinae por tener el opistosoma muy alargado (usualmente vermiforme). La mayoría de las hembras tienen las espermatecas alargadas, excepto A. mexicanus. Mientras que los machos, generalmente, tienen modificaciones en el cefalotórax (Exline y Levi 1962; Agnarsson 2004). A diferencia de otras especies de Ariamnes de Norteamérica, las hembras de A. mexicanus (Exline y Levi, 1962) se reconocen por tener las espermatecas en forma de pera. El macho de A. mexicanus se parece a A. attenuatus $\mathrm{O}$. Pickard-Cambridge, 1881, pero difiere por tener el émbolo en forma de rombo y tener el rádix extendido en su extremo distal y ligeramente tuberculado (Exline y Levi 1962).

La distribución actual de $A$. mexicanus incluye a México y Cuba (World Spider Catalog 2018). En el país está registrada para Jalisco (Durán-Barrón 2004), Nuevo León (Exline y Levi 1962) y San Luis Potosí (Exline y Levi 1962; Alvarez-Padilla Laboratory 2017). Aquí registramos la captura de A. mexicanus en el estado de Hidalgo y por tanto una ampliación de su distribución conocida en México.

\section{Ariamnes mexicanus (Exline y Levi, 1962)}

Fig. 1-3

Material examinado: México: Hidalgo, Mpio. Huejutla de Reyes, Ciudad de Huejutla de Reyes $\left(21^{\circ} 08^{\prime} 15.12^{\prime}\right.$ N N, 98²3'55.96" O, 140 msnm), 19 abril 2017, I. Martínez leg. 1 hembra depositada en la Colección de Arácnidos del Sureste de México (ECOSUR). El espécimen se obtuvo en una zona perturbada de bosque tropical perennifolio. Como dato importante, ésta hembra es más pequeña que la reportada por Exline y Levi (1962) y tiene las siguientes medidas (en mm): cefalotórax 1.92 largo, 0.86 ancho; pata I: 6.56 fémur, 5.12 patela-tibia, 3.80 metatarso y 1.50 tarso.

\section{AGRADECIMIENTOS}

A CONACYT por la Beca de Posgrado concedida a D. Chamé; a G.M. Suárez y J. Bueno quienes ayudaron en la adquisición de imágenes y en asuntos logísticos respectivamente que permitieron la culminación de este trabajo.

Recibido: 27 de julio de 2018

Aceptado: 25 de octubre de 2018

Primero en línea: 20 de diciembre 2018

Online First Publication: 20th December 2018

\section{LITERATURA CITADA}

Agnarsson, I. 2004. Morphological phylogeny of cobweb spiders and their relatives (Araneae, Araneoidea, Theridiidae). Zoological Journal of the Linnean Society, 141: 447-626. doi:10.1111/j.1096-3642.2004.00120.x

Alvarez-Padilla Laboratory. 2017. Biodiversity of Araneomorphae from Mexico. www.unamfcaracnolab. com. Fecha de consulta: 20 de julio de 2018

Durán-Barrón, C. G. 2004. Arañas de la Familia Theridiidae Sundevall 1833 (Arachnida: Araneae) de la Estación de Biología Chamela (pp. 1-14). En: García Aldrete, A.N., R. Ayala Barajas (Eds.). Artrópodos de Chamela. Instituto de Biología, Universidad Nacional Autónoma de México.

Exline H y H. W. Levi. 1962. American spiders of the genus Argyrodes (Araneae, Theridiidae). Bulletin of the Museum of Comparative Zoology Harvard 127(2): 75204

World Spider Catalog (2018). World Spider Catalog. Versión 19.5. http://wsc.nmbe.ch. Fecha de consulta: 20 de julio de 2018. doi: $10.24436 / 2$

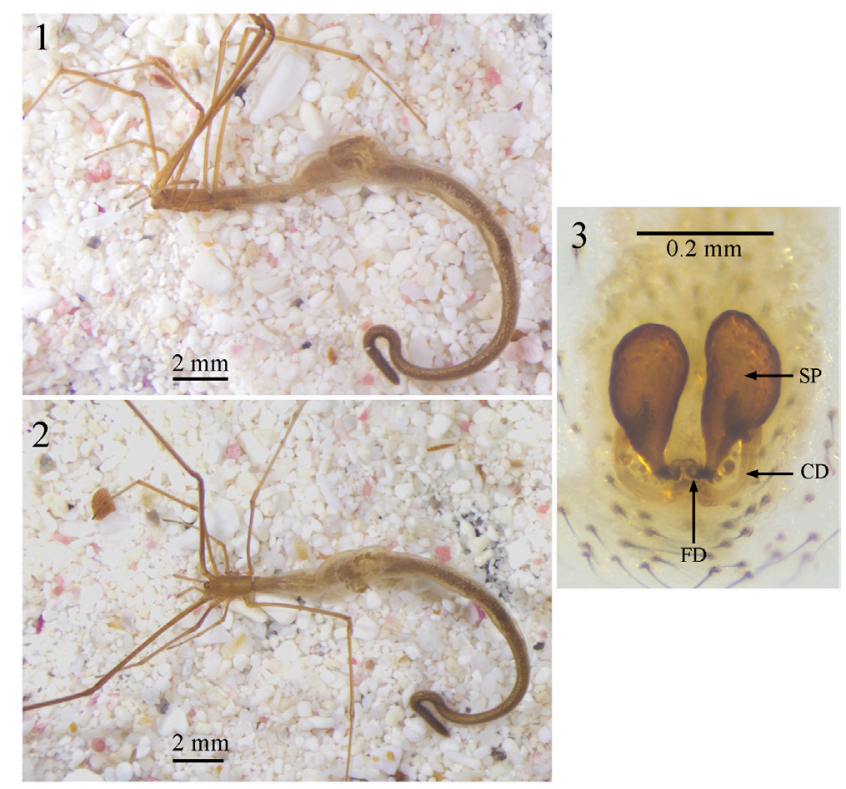

Figura 1-3. Ariamnes mexicanus (Exline y Levi, 1962). 1) Habitus, vista lateral, 2) Habitus, vista dorsal, 3) Epigynum, vista dorsal. 